\title{
Characterization of rickettsiae in ticks in northeastern China
}

\author{
Huanhuan Liu ${ }^{1 \dagger}$, Qihong Li ${ }^{2,3 \dagger}$, Xiaozhuo Zhang ${ }^{2 \dagger}$, Zhongyu Li ${ }^{1}$, Zedong Wang ${ }^{2}$, Mingxin Song ${ }^{4}$, Feng Wei ${ }^{1}$, \\ Shuchao Wang ${ }^{2^{*}}$ and Quan Liu ${ }^{2^{*}}$
}

\begin{abstract}
Background: Tick-borne rickettsioses are considered important emerging zoonoses worldwide, but their etiological agents, rickettsiae, remain poorly characterized in northeastern China, where many human cases have been reported during the past several years. Here, we determined the characteristics of Rickettsia spp. infections in ticks in this area.
\end{abstract}

Methods: Ticks were collected by flagging vegetation from Jilin and Heilongjiang provinces of northeastern China followed by morphological identification. The presence of Rickettsia spp. in ticks was detected by PCR targeting the 23S-5S ribosomal RNA intergenic spacer, citrate synthase ( $\mathrm{g} / \mathrm{t} A$ ) gene, and 190-kDa outer membrane protein gene (ompA). The newly-generated sequences were subjected to phylogenetic analysis using the software MEGA 6.0.

Results: The overall infection rate of Rickettsia spp. was $6.12 \%$. Phylogenetic analyses based on the partial gltA and ompA genes demonstrated that rickettsiae detected in the ticks belong to four species, including "Candidatus Rickettsia tarasevichiae", Rickettsia heilongjiangensis, Rickettsia raoultii, and a potential new species isolate. The associated tick species were also identified, i.e. Dermacentor nuttalli and Dermacentor silvarum for R. raoultii, Haemaphysalis concinna and Haemaphysalis longicornis for R. heilongjiangensis, and Ixodes persulcatus for " $\mathrm{Ca}$. R. tarasevichiae". All Rickettsia spp. showed significantly high infection rates in ticks from Heilongjiang when compared to Jilin Province.

Conclusion: Rickettsia heilongjiangensis, R. raoultii and "C $a$. R. tarasevichiae" are widely present in the associated ticks in northeastern China, but more prevalent in Heilongjiang Province. The data of this study increase the information on the distribution of Rickettsia spp. in northeastern China, which have important public health implications in consideration of their recent association with human diseases.

Keywords: Tick, Rickettsia, Rickettsiosis, Northeastern China

Abbreviations: rRNA, Ribosomal RNA; gltA, Citrate synthase gene; ompA, 190-kDa outer membrane protein gene

\section{Background}

Tick-transmitted diseases have become an increasing public health problem [1-3]. Tick-borne rickettsioses are considered important emerging zoonoses worldwide, due to tick distribution alterations, shifting climates, and accelerating urbanization $[4,5]$. These diseases share characteristic clinical features, including fever, asthenia,

\footnotetext{
*Correspondence: wsc1026@126.com; liuquan1973@hotmail.com

${ }^{\dagger}$ Equal contributors

${ }^{2}$ Military Veterinary Institute, Academy of Military Medical Sciences, Key Laboratory of Jilin Province for Zoonosis Prevention and Control, Changchun, People's Republic of China

Full list of author information is available at the end of the article
}

anorexia, nausea, headache, rash and occasional eschar formation at the site of the tick bite.

At least nine species or subspecies of tick-borne rickettsiae have been identified during the past 30 years in China, including Rickettsia heilongjiangensis, Rickettsia sibirica sp BJ-90, Rickettsia raoultii and "Candidatus Rickettsia tarasevichiae" [6-9]. Rickettsia heilongjiangensis was primarily identified in Suifenhe and Luobei of Heilongjiang Province in 1984, and isolated from the blood of a tick-bitten patient in the same place ten years later [10-12]. Since then, this organism has been detected or isolated in other countries, including Russia, Japan and Thailand [13-15]. Rickettsia heilongjangensis 
was first proven responsible for human disease in 1996, and 34 human cases have been reported [3]. Rickettsia sibirica strain BJ-90 was primarily detected in Dermacentor sinicus ticks from Beijing, and had not been considered as a pathogenic agent for humans until 2012 when an old farmer from Mudanjiang of Heilongjiang Province was diagnosed with infection of this organism [7]. Rickettsia raoultii, initially detected in Russia in 1999 and considered a novel species in 2008, is prevalent in various regions of Asia and Europe [16-19]. In 2009, $R$. raoultii was determined as a human pathogen in France [20]. In China, DNA of this bacterium was first detected in Jilin Province in 2008 [21]. Recently, $R$. raoultii has been found prevalent in Heilongjiang, Xinjiang and Tibet provinces [22-25]. However, the first human case of $R$. raoultii infection in China was reported in the northeast in 2014 [9]. "Ca R. tarasevichiae", belonging to the so-called ancestral group that was traditionally considered nonpathogenic, was first detected in Ixodes persulcatus ticks collected from various regions of Russia, and subsequently recorded in a wide territory from Estonia to Japan [26-28]. In 2013, specific DNA of "Ca. R. tarasevichiae" was detected in blood samples of five misdiagnosed patients in northeastern China [8].

More than 500 human cases have been reported in China in the past 13 years, mostly in the northeastern region of the country, suggesting an increasing risk of Rickettsia infection. We therefore conducted this study to detect and characterize the rickettsiae in ticks collected in northeastern China.

\section{Methods}

\section{Collection of ticks}

During April and May 2015, ticks were collected by flagging vegetation in nine regions of northeastern China, including Jilin $\left(42^{\circ} 39^{\prime}-43^{\circ} 20^{\prime} \mathrm{N}, 126^{\circ} 12^{\prime}-127^{\circ} 23^{\prime} \mathrm{E}\right)$, Dunhua $\left(42^{\circ} 27^{\prime}-43^{\circ} 2^{\prime} \mathrm{N}, 129^{\circ} 50^{\prime}-130^{\circ} 44^{\prime} \mathrm{E}\right)$ and Hunchun $\left(42^{\circ} 47^{\prime}-43^{\circ} 6^{\prime} \mathrm{N}, 130^{\circ} 6^{\prime}-130^{\circ} 12^{\prime} \mathrm{E}\right)$ located in Jilin Province, and Yichun $\left(47^{\circ} 24^{\prime}-48^{\circ} 3^{\prime} \mathrm{N}, 128^{\circ} 23^{\prime}-129^{\circ} 37^{\prime} \mathrm{E}\right)$, Jiamusi $\left(46^{\circ} 43^{\prime}-47^{\circ} 11^{\prime} \mathrm{N}, 133^{\circ} 12^{\prime}-133^{\circ} 56^{\prime} \mathrm{E}\right)$, Shuangyashan $\left(46^{\circ}\right.$ $\left.27^{\prime}-46^{\circ} 58^{\prime} \mathrm{N}, 131^{\circ} 12^{\prime}-131^{\circ} 23^{\prime} \mathrm{E}\right)$, Tongjiang $\left(47^{\circ} 43^{\prime}-48^{\circ} 3^{\prime}\right.$ $\left.\mathrm{N}, \quad 133^{\circ} 29^{\prime}-133^{\circ} 44^{\prime} \mathrm{E}\right)$, Hulin $\left(45^{\circ} 33^{\prime}-45^{\circ} 54^{\prime} \mathrm{N}, 132^{\circ}\right.$ $\left.49^{\prime}-133^{\circ} 23^{\prime} \mathrm{E}\right)$ and Suifenhe $\left(44^{\circ} 23^{\prime} \mathrm{N}, 131^{\circ} 9^{\prime} \mathrm{E}\right)$ situated in Heilongjiang Province (Fig. 1). The tick species were identified following morphological criteria as described previously or using molecular biology tools after PCR targeting the $16 \mathrm{~S}$ ribosomal RNA gene with the forward primer TickHF (5'-GGT ATT TTG ACT ATA CAA AGG TAT TG-3') and the reverse primer TickHR (5'-TTA TTA CGC TGT TAT CCC TAG AGT ATT-3') [29].

\section{Detection of rickettsiae}

The sampled ticks were pooled, approximately 15 ticks per pool, based on the tick species and sampling sites. After washing with $70 \%$ ethanol and double distilled water, the pooled ticks were homogenized in $1 \mathrm{ml}$ sterile PBS. DNA was extracted from $200 \mu$ tick homogenates using TIANamp Genomic DNA Purification System (TIANGEN, Beijing, China) according to the manufacturer's instructions. The tick pools were initially screened for the presence of Rickettsia spp. by amplifying the 23S-5S rRNA intergenic spacer by polymerase chain reaction (PCR) using the primers $\mathrm{RCK} / 23-5-\mathrm{F}$ and $\mathrm{RCK} / 23-5-\mathrm{R}$ as described previously [30]. Doubledistilled water and a previously determined positive sample were used as negative and positive controls, respectively.

The positive pools were subsequently analyzed by amplifying the partial citrate synthase ( $g l t A)$ gene and outer membrane protein A (ompA) gene of Rickettsia spp. by PCR with the primers CS2d and CSEndr for gltA targeting a 1289 bp fragment, and Rr190.70p and Rr190.602n for ompA targeting a 533 bp fragment [8, 31]. The PCR products were cloned into pMD18-T vector (Takara, Dalian, China) and sequenced.

\section{Phylogenetic analysis}

The newly-generated sequences were aligned exclusively, or together with those retrieved from the GenBank database using the software ClustalW 2.0. Phylogenetic trees were generated in a Maximum Likelihood analysis using the software Molecular Evolutionary Genetics Analysis (MEGA) version 6.0 [11].

\section{Statistical analysis}

The infection rates of Rickettsia spp. in ticks were calculated using the software PooledInfRate version 4.0 (By Biggerstaff, Brad J., a Microsoft ${ }^{\circledR}$ Office Excel $^{\odot}$ Add-In to compute prevalence estimates from pooled samples. Centers for Disease Control and Prevention, Fort Collins, CO, USA, 2009). The software provides three computing methods for infection rate estimation, including biascorrected maximum likelihood estimation (Bias-corrected MLE) and minimal infection rate (MIR). The former exhibits better accuracy than the latter, but requires that not all the pools are positive. Statistical significance was evaluated by Fisher's exact test and Chi-square test; $P<0.05$ is considered significant.

\section{Results}

A total of 2928 ticks, including 2813 adults and 115 nymphs, were collected from Jilin and Heilongjiang provinces of northeastern China (Fig. 1). In particular, the nymphs were exclusively collected from Jingxin town $\left(42^{\circ} 30^{\prime} \mathrm{N}, 130^{\circ} 38^{\prime} \mathrm{E}\right)$ in Jilin Province. The species of ticks were morphologically determined as Dermacentor nuttalli $(n=253)$, Dermacentor silvarum $(n=204)$, Haemaphysalis concinna $(n=412)$, Haemaphysalis longicornis ( $n=390,275$ adults and 115 nymphs) and Ixodes 


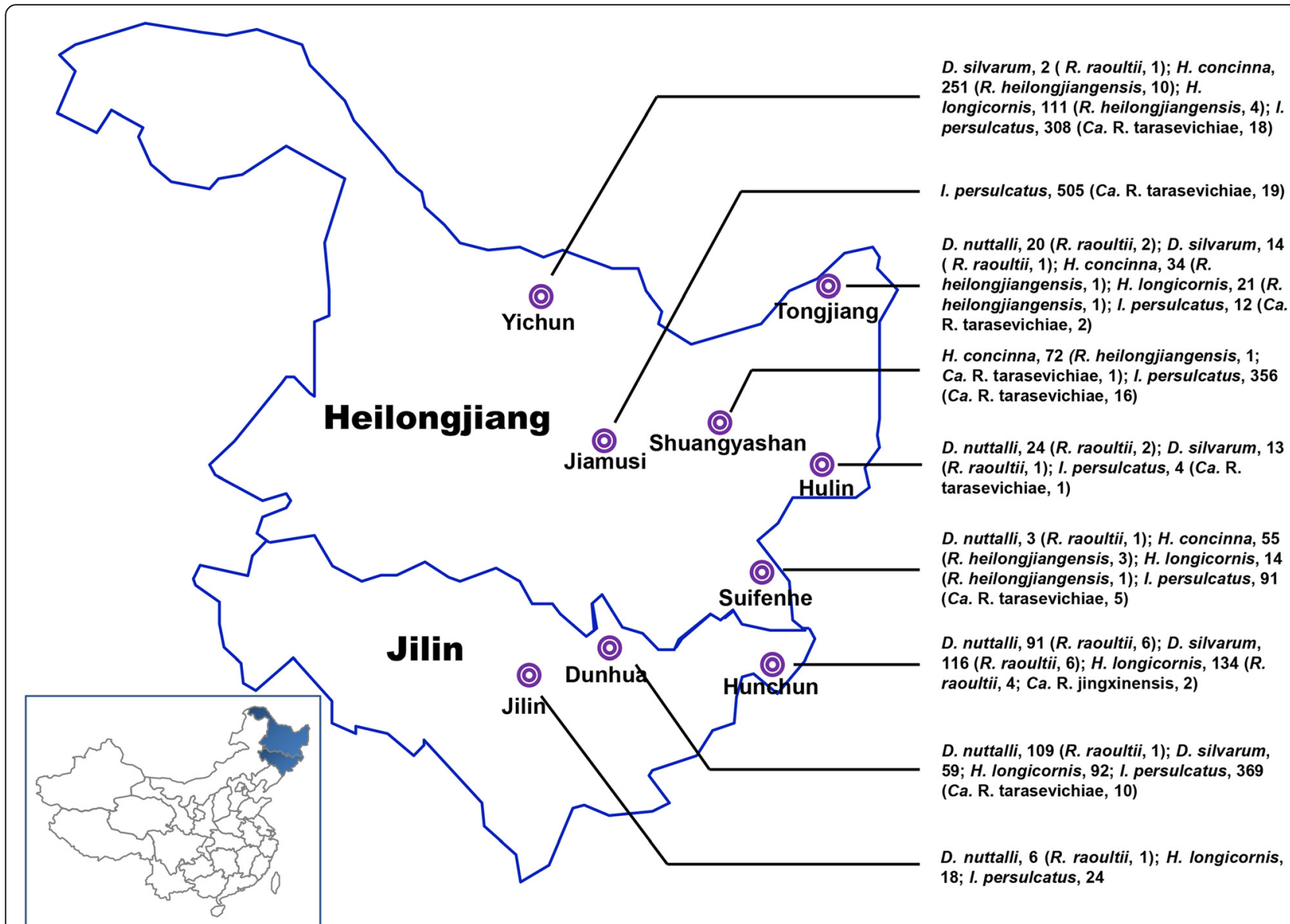

Fig. 1 Sampling sites, ticks and rickettsiae. Ticks were collected from various regions in Jilin and Heilongjiang provinces. Tick species and the rickettsiae detected are shown in parentheses

persulcatus $(n=1669)$. Based on species and sampling site, the identified ticks were subsequently assigned into 204 pools, of which 201 were adults and three were nymphs (detailed in Additional file 1: Table S1). In order to ensure the accuracy of identification of tick species, we also analyzed the partial sequence of $16 \mathrm{~S}$ ribosomal RNA gene of a portion of ticks using BLAST. The sequences (354 nt, GenBank accession no. KX305956) derived from five tick pools which were morphologically determined as I. persulcatus were genetically identical to one another and presented $100 \%$ similarity to that of $I$. persulcatus isolate Irk5m (accession no. JF934741.1). The partial 16S rRNA gene sequences (252 nt, accession no. KX305957) obtained from $D$. nuttalli pools were also identical to each other but differed at two nucleotide positions from that of the nearest tick species $(D$. nuttalli isolate XJ088, accession no. JX051114.1). The three pools of nymphs and the adult $H$. longicormis ticks shared the same partial nucleotide sequence (127 nt, accession no. KX305958) of the 16S rRNA gene that was most related ( $99 \%$ similarity) to the sequence of $H$. longicormis isolate YN07 (accession no. JX051064.1). With the exception of $H$. concinna absent in samples from Jilin, all these tick species were found in both provinces. Dermacentor species were more prevalent (Pearson Chi-square test; $\left.X^{2}=564.0, d f=1, P<0.0001\right)$ in Jilin $(37.4 \%)$ in comparison with Heilongjiang $(4.0 \%)$, where I. persulcatus was the predominant tick species (Table 1).

To investigate the presence of Rickettsia spp. in tick samples, molecular screening was first performed using the universal primer set. In total, 122 tick pools out of 2928 (6.12 \%) ticks were found positive for Rickettsia spp. To identify the Rickettsia spp. in these positive samples, partial gltA (1289 bp) and ompA (533 bp) gene sequences were further obtained and sequenced. Phylogenetic analysis revealed that these sequences could be clustered into four clades (Additional file 2: Figure S1). After BLAST on the NCBI website, sequences in the GenBank database most similar to the query sequences were retrieved and used for phylogenetic analysis, revealing that clades 1,2 and 4 were corresponding to "Ca. R. tarasevichiae", $R$. heilongjiangensis and $R$. raoultii, respectively (Fig. 2 and Fig. 3). Two identical 
Table 1 PCR survey results for ticks tested for rickettsiae, northeastern China, 2015. Infection rates of Rickettsia spp. in ticks were calculated following the Bias-corrected MLE method in the software Pooledinfrate, version 4.0; $95 \%$ confidence intervals (Cl) are presented in brackets

\begin{tabular}{|c|c|c|c|c|c|c|c|c|c|c|c|c|}
\hline \multirow[t]{2}{*}{ Tick species } & \multirow{2}{*}{$\begin{array}{l}\text { No. of ticks } \\
\text { tested }\end{array}$} & \multirow{2}{*}{$\begin{array}{l}\text { Total no. }(\%) \text { ticks } \\
\text { positive }[95 \% \mathrm{Cl}]\end{array}$} & \multicolumn{5}{|l|}{ Jilin } & \multicolumn{5}{|l|}{ Heilongjiang } \\
\hline & & & $\begin{array}{l}\text { Total no. of } \\
\text { ticks tested }\end{array}$ & $\begin{array}{l}\text { Total no. (\%) ticks } \\
\text { positive }[95 \% \mathrm{Cl}]\end{array}$ & $\begin{array}{l}\text { R. r. (\%) } \\
{[95 \% \mathrm{Cl}]}\end{array}$ & $\begin{array}{l}\text { C. R. j. (\%) } \\
{[95 \% \mathrm{Cl}]}\end{array}$ & $\begin{array}{l}\text { C. R.t. (\%) } \\
{[95 \% \mathrm{Cl}]}\end{array}$ & $\begin{array}{l}\text { Total no. of ticks } \\
\text { tested }\end{array}$ & $\begin{array}{l}\text { Total no. of (\%) } \\
\text { ticks positive }\end{array}$ & $\begin{array}{l}\text { R. r. }(\%) \\
{[95 \% \mathrm{Cl}]}\end{array}$ & $\begin{array}{l}\text { R. h. (\%) } \\
{[95 \% \mathrm{Cl}]}\end{array}$ & $\begin{array}{l}\text { C. R.t. (\%) } \\
{[95 \% \mathrm{Cl}]}\end{array}$ \\
\hline $\begin{array}{l}\text { Dermacentor } \\
\text { nuttalli }\end{array}$ & 253 & $\begin{array}{l}13(7.45) \\
{[4.30-12.59]}\end{array}$ & 206 & $\begin{array}{l}8(5.16) \\
{[2.48-10.02]}\end{array}$ & $\begin{array}{l}8(5.16) \\
{[2.48-10.02]}\end{array}$ & 0 & 0 & 47 & $5(10.64)^{a}$ & $5(10.64)^{a}$ & 0 & 0 \\
\hline $\begin{array}{l}\text { Dermacentor } \\
\text { silvarum }\end{array}$ & 204 & $\begin{array}{l}9(6.07) \\
{[3.10-11.37]}\end{array}$ & 175 & $\begin{array}{l}6(4.42) \\
{[1.86-9.44]}\end{array}$ & $\begin{array}{l}6(4.42) \\
{[1.86-9.44]}\end{array}$ & 0 & 0 & 29 & $3(10.30)^{a}$ & $3(10.30)^{a}$ & 0 & 0 \\
\hline $\begin{array}{l}\text { Haemaphysalis } \\
\text { concinna }\end{array}$ & 412 & $\begin{array}{l}16(5.46) \\
{[3.28-8.80]}\end{array}$ & 0 & 0 & 0 & 0 & 0 & 412 & $\begin{array}{l}16(5.46) \\
{[3.28-8.80]}\end{array}$ & 0 & $\begin{array}{l}15(4.96) \\
{[2.93-8.09]}\end{array}$ & $\begin{array}{l}1(0.24) \\
{[0.01-1.18]}\end{array}$ \\
\hline $\begin{array}{l}\text { Haemaphysalis } \\
\text { longicornis }\end{array}$ & 390 & $\begin{array}{l}12(3.91) \\
{[2.23-6.59]}\end{array}$ & 244 & $\begin{array}{l}6(2.89) \\
{[1.30-5.99]}\end{array}$ & $\begin{array}{l}4(1.58) \\
{[0.58-3.61]}\end{array}$ & $\begin{array}{l}2(0.92) \\
{[0.16-3.2]}\end{array}$ & 0 & 146 & $\begin{array}{l}6(5.42) \\
{[2.29-11.64]}\end{array}$ & 0 & $\begin{array}{l}6(5.42) \\
{[2.29-11.64]}\end{array}$ & 0 \\
\hline Ixodes persulcatus & 1,669 & $\begin{array}{l}72(6.53) \\
{[5.16-8.22]}\end{array}$ & 393 & $\begin{array}{l}10(3.12) \\
{[1.61-5.62]}\end{array}$ & 0 & 0 & $\begin{array}{l}10(3.12) \\
{[1.61-5.62]}\end{array}$ & 1,276 & $\begin{array}{l}62(7.95) \\
{[6.16-10.22]}\end{array}$ & 0 & 0 & $\begin{array}{l}62(7.95) \\
{[6.16-10.22]}\end{array}$ \\
\hline Total & 2,928 & $\begin{array}{l}122(6.12) \\
{[5.13-7.29]}\end{array}$ & 1,018 & $\begin{array}{l}30(3.79) \\
{[2.64-5.34]}\end{array}$ & $\begin{array}{l}18(1.95) \\
{[1.22-2.99]}\end{array}$ & $\begin{array}{l}2(0.20) \\
{[0.04-0.67]}\end{array}$ & $\begin{array}{l}10(1.05) \\
{[0.54-1.87]}\end{array}$ & 1,910 & $\begin{array}{l}92(7.66) \\
{[6.23-9.39]}\end{array}$ & $\begin{array}{l}8(0.42) \\
{[0.20-0.80]}\end{array}$ & $\begin{array}{l}21(1.16) \\
{[0.76-1.78]}\end{array}$ & $\begin{array}{l}63(4.36) \\
{[3.39-5.54]}\end{array}$ \\
\hline
\end{tabular}

Abbreviations: R. r., Rickettsia raoultii; C. R. j., "Candidatus Rickettsia jingxinensis"; C. R. t., "Candidatus Rickettsia tarasevichiae"; R. h., Rickettsia heilongjiangensis

anfection rates are calculated using the MIR method 


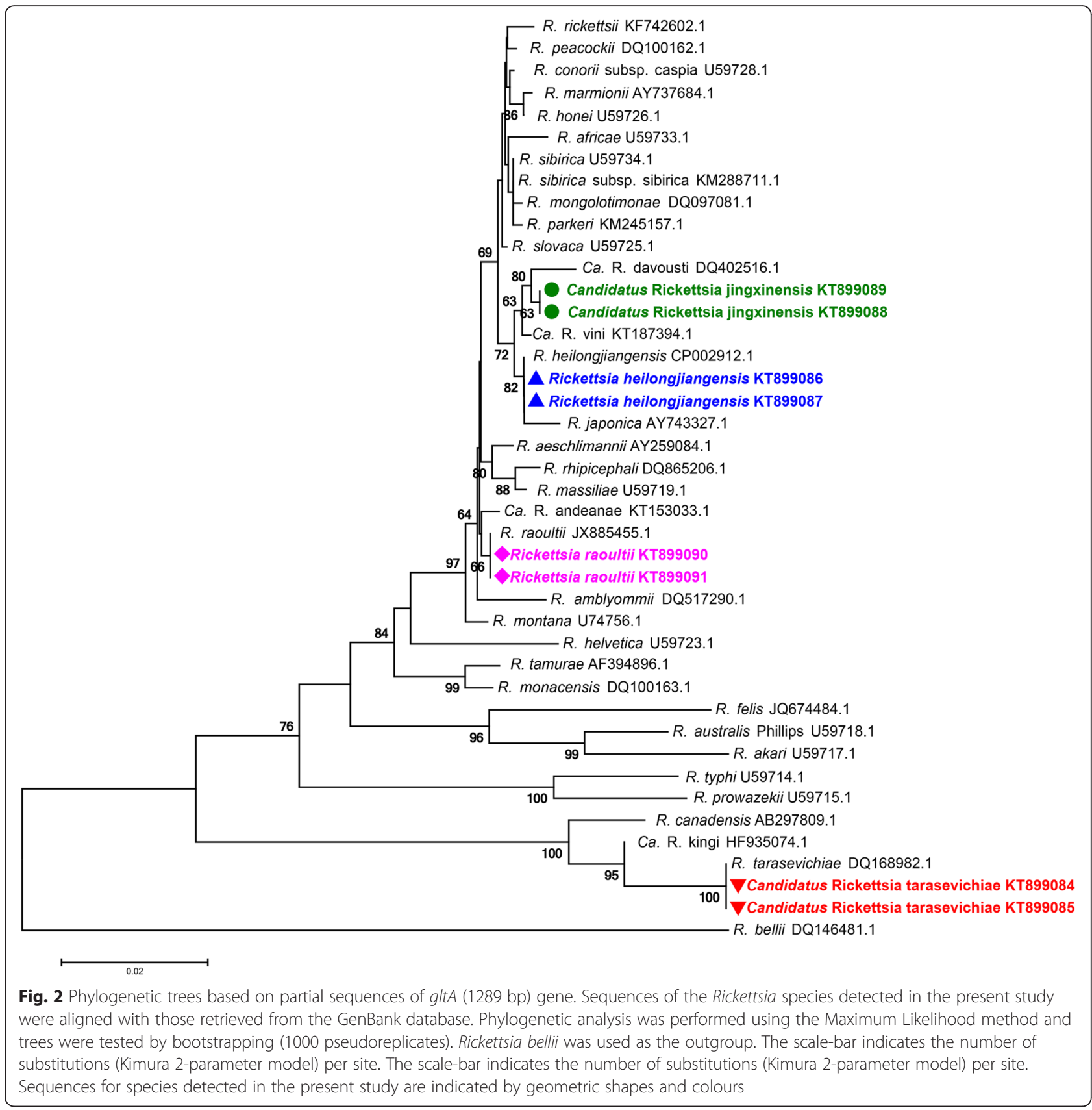

sequences obtained from $H$. longicornis collected in Jingxin town of Hunchun city constituted the clade 3. The affirmatory species of Rickettsia most-related to clade 3 was "Candidatus Rickettsia vini" which shared $96.6 \%$ nucleotide similarity of ompA sequence and $99.7 \%$ of gltA sequence. Current criteria for sequence-based classification of a Rickettsia species as a new "Candidatus Rickettsia" species requires the sequence similarity of the newly identified species with the established Rickettsia spp. should be: $<99.9 \%$ for $g l t A$ and $<98.8 \%$ for ompA [11]. Phylogenetic analyses based on gltA and ompA sequence showed the clade 3 as an independent clade (Fig. 2 and
Fig. 3). These results suggest that species in the clade 3 could be a potential new Rickettsia species. We propose to provisionally designate it as "Candidatus Rickettsia jingxinensis".

The overall infection rate of rickattsiae in Dermacentor ticks in Jilin and Heilongjiang provinces (4.42-5.16\% and $10.30-10.64 \%$, respectively) were higher than those of the other tick species $(0-3.12 \%$ and $5.42-7.95 \%$, respectively). The infection rate of rickettsiae in ticks from Heilongiiang were significantly higher than that of Jilin (Pearson Chi-square test; $X^{2}=5.355, d f=1, P=$ 0.0207) (Table 1). 


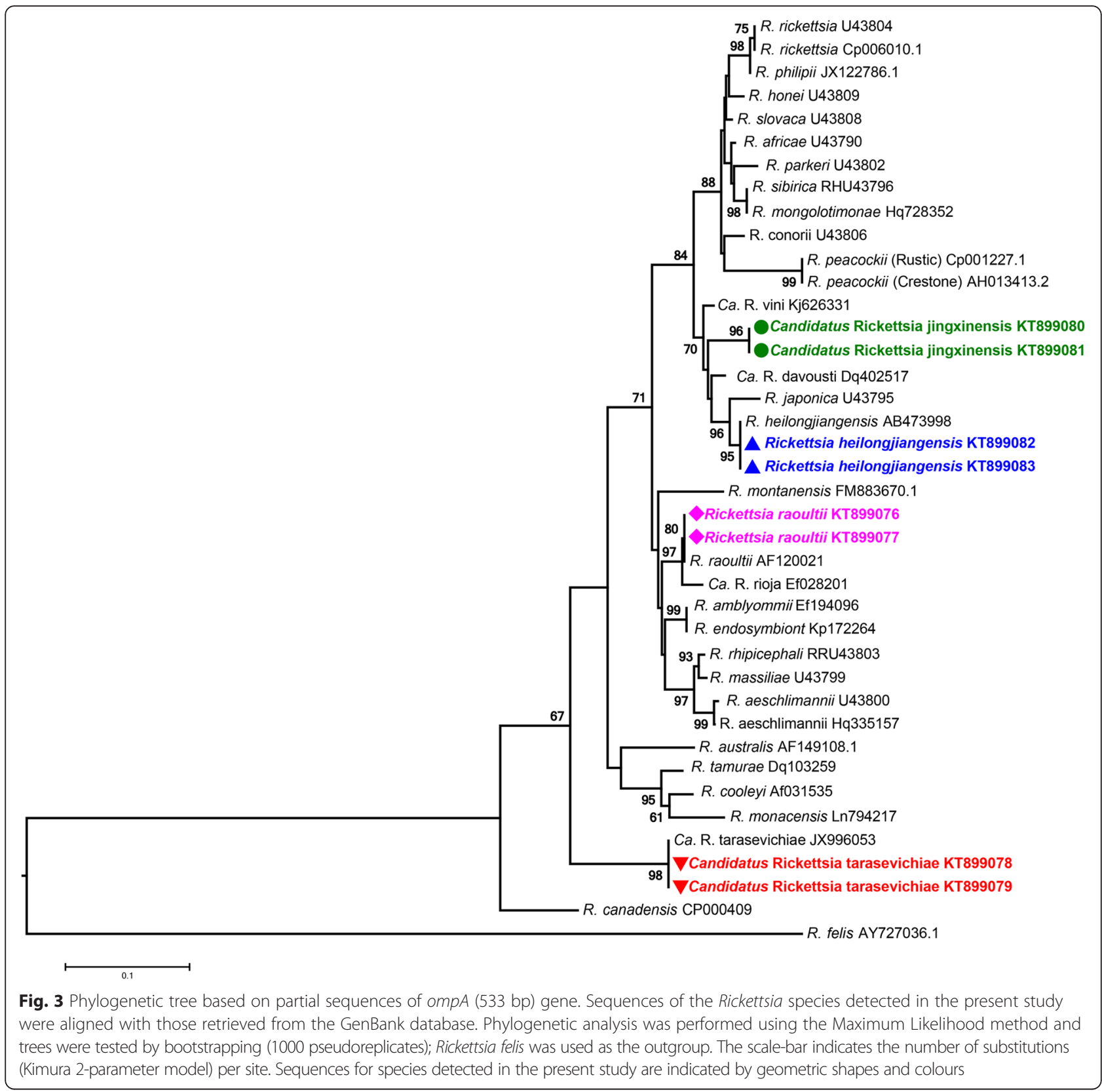

Rickettsia raoultii was detected with comparable infection rate in both $D$. nuttalli and $D$. silvarum with infection rate strikingly higher in Heilongjiang (10.30$10.64 \%)$ as compared to Jilin (4.42-5.16 \%) (Fisher's exact test; $\left.\chi^{2}=6.595, d f=1, P=0.017\right)$. Haemaphysalis longicormis from Jilin Province was also detected positive $(1.58 \%)$ for $R$. raoultii (Table 1$)$. The potential new Rickettsia species " $C a$. R. jingxinensis" was merely found in two tick pools of nymphs of $H$. longicormis from Jingxin in Jilin Province with an infection rate of $0.92 \%$. DNA of $R$. heilongjiangensis was exclusively detected in Haemaphysalis ticks from Heilongiiang Province with infection rate of $4.96 \%$ in $H$. concinna and $5.42 \%$ in $H$. longicormis. "Ca. R. tarasevichiae” DNA was only present in I. persulcatus with one exception in H. longicormis collected from Shuangyashan of Heilongjiang Province (Fig. 1).

The representative partial sequences of $g l t A$ and ompA gene in the present study have been deposited to Genbank (see accession numbers in Table 2).

\section{Discussion}

To date, twenty-one tick species of seven genera have been reported in northeastern China [32]. In the present study, we only collected five tick species, including $D$. nuttalli, $D$. silvarum, $H$. concinna, $H$. longicornis and $I$. 
Table 2 GenBank accession numbers of the sequences generated in the present study

\begin{tabular}{lll}
\hline Species & gltA & ompA \\
\hline R. raoultii in D. nuttalli & KT899090 & KT899076 \\
R. raoultii in H. longicornis, & KT899091 & KT899077 \\
"Candidatus R. tarasevichiae" in H. concinna & KT899084 & KT899078 \\
"Candidatus R. tarasevichiae" in I. persulcatus & KT899085 & KT899079 \\
"Candidatus R. jingxinensis" in H. longicornis & KT899088 & KT899080 \\
R. heilongjiangensis in H. concinna & KT899086 & KT899082 \\
R. heilongjiangensis in H. longicornis & KT899087 & KT899083 \\
\hline
\end{tabular}

persulcatus. We also demonstrated that the tick population in Jilin Province is different from that of Heilongjiang Province. For example, Dermacentor species are predominant in Jilin, compared with Heilongjiang Province. Haemaphysalis concinna had been reported in Hunchun and Dunhua (Jilin Province) [32], but it was not found in this study. The possible reasons may come from the limitation of sampling period and regions, and altered tick population induced by the interruption of nature balance [33].

All of the tick species identified in our study can function as vectors that could transmit various pathogens to humans and animals. For instance, $H$. longicornis is a vector for $R$. heilongjiangensis, "Candidatus Rickettsia hebeiii”, Ehrilchia chaffeensis, Borrelia garinii and Babesia mircroti [3]. In northeastern China, Rickettsia spp. spread by human-bitten ticks could be a serious public health problem, and several Rickettsia spp. have been identified or isolated from ticks or patients, including $R$. heilongjiangensis, Rickettsia sibrica, Rickettsia japonica, $R$. raoultii and "Ca. R. tarasevichiae" during the past 30 years [3]. In the current study, three Rickettsia spp., including $R$. heilongjiangensis, $R$. raoultii, “Ca. R. tarasevichiae", and a potential new species "Ca. R. jingxinensis", were detected in ticks, with an overall infection rate of $6.12 \%$. Previous reports showed that Rickettsia infection rates ranged from 1.53 to $32.25 \%$ in a certain species, or a certain vector, or a certain origin of northeastern China [21, 34]. Intriguingly, the infection rates of rickettsiae in Heilongjiang Province were found to be strikingly higher than those of Jilin Province in the present study. The geography-based dissimilarity of Rickettsia presence provides new insight for the prevention and control of tick-borne rickettsioses. In northeastern China, $R$. heilongjiangensis was detected in three counties of Heilongjiang with an infection rate of $4.7 \%$ [15]. Rickettsia heilongjiangensis was initially detected in D. silvarum and Haemaphysalis ticks [12], but only found in the latter in this study, which confirmed the previous finding that Haemaphysalis ticks were the major vector of $R$. heilongjiangensis [35]. Despite the presence of $R$. heilongjiangensis in Jilin Province was proven in rodent animals and humans [15], we only detected it in ticks from Heilongjiang Province in the current study. This result suggests $R$. heilongjiangensis could be more prevalent in Heilongjiang Province. At the China-Russia border, $R$. raoultii was considered to be the predominant Rickettsia in D. silvarum; this was confirmed in the present study [22]. Furthermore, we also demonstrated that in Jilin and Heilongjiang provinces, $R$. raoultii appeared to be predominant in $D$. nuttalli, as already shown in a study in Mongolia [36]. Although $R$. raoultii was detected in other tick species, such as Haemaphysalis erinacei and I. persulcatus, we did not amplify DNAs of this Rickettsia species from ticks except for Dermacentor species, suggesting that Dermacentor species may be the major vector for $R$. raoultii, as stated in the previous studies [22, 23]. "Ca. R. tarasevichiae" was recently found in patients and $I$. persulcatus in Heilongjiang Province in China, renewing the old concept that members of the ancestral group of Rickettsia were nonpathogenic [8, 34]. In this study, the presence of "Ca. R. tarasevichiae" was extended from Heilongjiang to Jilin Province. For the first time, we detected "Ca. R. tarasevichiae" in $H$. longicornis in China, which confirmed the presence of this organism in tick species besides I. persulcatus, as reported in Russia [37].

In addition, we also detected a new variant " $\mathrm{Ca}$. R. jingxinensis". Phylogenetic analyses based on both ompA and glt $A$ gene sequences indicated this may be a new species. However, additional studies are required to verify this possibility. "Ca. R. jingxinensis" is closely related to "Ca. Rickettsia vini" and "Ca. Rickettsia davousti". Although the Candidatus species have not been identified as human or animal pathogens despite a wide geographic distribution, we could not exclude the potential threat for humans and animals [38, 39].

Our study had some limitations. First, our investigation was subjected to bias because the infection rates were calculated in pooled samples, and we could not exclude the possibility of various strains in each pool. Therefore, the actual infection rates might be higher than stated above. Second, since our interests mainly focused on the infection rates in different areas and tick species in northeastern China, we did not identify the sex of the ticks. Thus, it is impossible to ascertain the precise infection rate of Rickettsia spp. based on the vector gender in this study.

\section{Conclusion}

We determined that $D$. nuttalli, $D$. silvarum, $H$. concinna, $H$. longicornis and especially $I$. persulcatus were the major tick species, and acting mainly as vectors for $R$. raoultii, $R$. heilongjiangensis and “ $C a$. R. tarasevichiae", respectively, in northeastern China. These rickettsiae were more prevalent in Heilongjiang as compared to Jilin Province. These data 
increase the information on the distribution of rickettsiae in northeastern China, which have important public health implications in consideration of their recent association with human diseases.

\section{Additional files}

Additional file 1: Table S1. Ticks and tick-borne Rickettsia spp.
(DOCX $23 \mathrm{~kb})$

Additional file 2: Figure S1. Phylogenetic analysis of the partial ompA (533 bp) sequences obtained in this study. Targeted fragments of ompA gene of all of the positive samples were analyzed through the Maximum Likelihood method using MEGA 6.0 [40]. Phylogenic tree was tested by bootstrapping (1000 pseudoreplicates). Sequences in the tree are identified by sample number, tick species, and sampling site. (TIF $5444 \mathrm{~kb}$ )

\section{Acknowledgements}

Not applicable.

\section{Funding}

This study was supported by the National Science \& Technology Pillar Program during the Twelfth Five-year Plan Period (2013BAD12B04), the Military Medical Health project in China (13CXZ024), the National Key Research Program during the Thirteenth Five-year Plan Period (2016YFC1201602) and the Science and Technology Basic Work Program from the Ministry of Science and Technology of China (2013FY113600). The funders of this study had no role in study design, data collection, data analysis, data interpretation, or writing of the paper. The corresponding authors had access to the data in the study and had final responsibility for the decision to submit for publication.

\section{Availability of data and materials}

All data generated or analyzed in this study are included in the article and its Additional files 1 and 2. Sequences were submitted to the GenBank database under accession numbers KT899076-KT899091 and KX305956-KX305958.

\section{Authors' contributions}

Project designing: QL, SW and ZW; sample collection: QL, ZL and MS; data acquisition: HL, XZ, SW, ZL and Q-HL; data analysis: QL, SW, ZW, FW and $\mathrm{Q}-\mathrm{HL}$; manuscript preparation: SW and QL; manuscript revision: $\mathrm{QL}, \mathrm{SW}$, FW, MS and Q-HL. All authors read and approved the final version of the manuscript.

\section{Competing interests}

The authors declare that they have no competing interests.

\section{Consent for publication}

Not applicable.

\section{Ethics approval and consent to participate}

Not applicable.

\section{Author details}

${ }^{1}$ College of Life Science, Jilin Agricultural University, Changchun, People's Republic of China. ${ }^{2}$ Military Veterinary Institute, Academy of Military Medical Sciences, Key Laboratory of Jilin Province for Zoonosis Prevention and Control, Changchun, People's Republic of China. ${ }^{3}$ Affiliated hospital of Academy of Military Medical Science, Beijing, People's Republic of China. ${ }^{4}$ College of Veterinary Medicine, Northeast Agricultural University, Harbin, People's Republic of China.

\section{Received: 27 November 2015 Accepted: 19 August 2016}

Published online: 13 September 2016

\section{References}

1. Liu Q, He B, Huang SY, Wei F, Zhu XQ. Severe fever with thrombocytopenia syndrome, an emerging tick-borne zoonosis. Lancet Infect Dis. 2014;14(8):763-72.
2. Gong SS, He B, Wang ZD, Shang LM, Wei F, Liu Q, et al. Nairobi sheep disease virus RNA in ixodid ticks, China, 2013. Emerg Infect Dis. 2015;21(4):718-20

3. Fang LQ, Liu K, Li XL, Liang S, Yang Y, Yao HW, et al. Emerging tick-borne infections in mainland China: an increasing public health threat. Lancet Infect Dis. 2015;15(12):1467-79.

4. Dantas-Torres F, Chomel BB, Otranto D. Ticks and tick-borne diseases: a One Health perspective. Trends Parasitol. 2012;28(10):437-46.

5. Parola P, Paddock CD, Raoult D. Tick-borne rickettsioses around the world: emerging diseases challenging old concepts. Clin Microbiol Rev. 2005;18(4):719-56.

6. Wu XB, Na RH, Wei SS, Zhu JS, Peng HJ. Distribution of tick-borne diseases in China. Parasit Vectors. 2013;6:119.

7. Jia N, Jiang JF, Huo QB, Jiang BG, Cao WC. Rickettsia sibirica subspecies sibirica BJ-90 as a cause of human disease. New Engl J Med. 2013;369(12): $1176-78$.

8. Jia N, Zheng YC, Jiang JF, Ma L, Cao WC. Human infection with Candidatus Rickettsia tarasevichiae. N Engl J Med. 2013;369(12):1178-80.

9. Jia N, Zheng YC, Ma L, Huo QB, Ni XB, Jiang BG, et al. Human Infections with Rickettsia raoultii, China. Emerg Infect Dis. 2014;20(5):866-68.

10. Wu YM, Zhang ZQ, Feng L. Rickettsia heilongjiangii and Heilongjiangii tickborne spotted fever. J Microbiol. 2005;6(25):95-97 (in Chinese).

11. Fournier PE, Dumler JS, Greub G, Zhang J, Wu Y, Raoult D. Gene sequencebased criteria for identification of new Rickettsia isolates and description of Rickettsia heilongjiangensis sp. nov. J Clin Microbiol. 2003;41(12):5456-65.

12. Luo D, Wu YM, Wang B, Liu GD, Li JZ. A new member of the spotted fever group of rickettsiae - Rickettsia heilongjiangii. Chin J Microbiol Immunol. 1985;7(5):250-53 (in Chinese).

13. Ando S, Kurosawa M, Sakata A, Fujita H, Sakai K, Sekine M, et al. Human Rickettsia heilongjiangensis infection, Japan. Emerg Infect Dis. 2010;16(8):1306-08.

14. Shpynov SN, Fournier PE, Rudakov NV, Samoilenko IE, Reshetnikova TA, Yastrebov VK, et al. Molecular identification of a collection of spotted fever group rickettsiae obtained from patients and ticks from Russia. Am J Trop Med Hyg. 2006;74(3):440-43.

15. Wu YM, Zhang ZQ, Wang HJ, Yang Q, Feng L, Wang JW. Investigation on the epidemiology of Far-East tick-borne spotted fever in the Northeastern area of China. Chin J Epidemiol. 2008;29(12):1173-75 (in Chinese).

16. Rydkina E, Roux V, Fetisova N, Rudakov N, Gafarova M, Tarasevich I, et al. New rickettsiae in ticks collected in territories of the former Soviet Union. Emerg Infect Dis. 1999;5(6):811-14.

17. Mediannikov O, Matsumoto K, Samoylenko I, Drancourt M, Roux V, Rydkina E, et al. Rickettsia raoultii sp. nov., a spotted fever group rickettsia associated with Dermacentor ticks in Europe and Russia. Int I Syst Evol Microbiol. 2008;58(Pt 7):1635-39.

18. Portillo A, Santibanez S, Garcia-Alvarez L, Palomar AM, Oteo JA. Rickettsioses in Europe. Microbes Infect. 2015;17(11-12):834-38.

19. Orkun O, Karaer Z, Cakmak A, Nalbantoglu S. Spotted fever group rickettsiae in ticks in Turkey. Ticks Tick Borne Dis. 2014;5(2):213-18.

20. Parola P, Rovery C, Rolain JM, Brouqui P, Davoust B, Raoult D. Rickettsia slovaca and $R$. raoultii in tick-borne rickettsioses. Emerg Infect Dis. 2009;15(7):1105-08.

21. Cao WC, Zhan L, De Vlas SJ, Wen BH, Yang H, Richardus JH, et al. Molecular detection of spotted fever group Rickettsia in Dermacentor silvarum from a forest area of northeastern China. J Med Entomol. 2008;45(4):741-44.

22. Wen J, Jiao D, Wang JH, Yao DH, Liu ZX, Zhao G, et al. Rickettsia raoultii, the predominant Rickettsia found in Dermacentor silvarum ticks in China-Russia border areas. Exp Appl Acarol. 2014;63(4):579-85.

23. Guo LP, Mu LM, Xu J, Jiang SH, Wang AD, Chen CF, et al. Rickettsia raoultii in Haemaphysalis erinacei from marbled polecats, China-Kazakhstan border. Parasit Vectors. 2015;8:461.

24. Sun X, Zhang GL, Liu R, Liu XM, Zhao Y, Zheng Z. Molecular epidemiological study of Rickettsia raoultii in ticks from Xinjiang, China. Chin J Epidemiol. 2013;34(7):756-57 (in Chinese).

25. Wang Y, Liu Z, Yang J, Chen Z, Liu J, Li Y, et al. Rickettsia raoultii-like bacteria in Dermacentor spp. ticks, Tibet, China. Emerg Infect Dis. 2012;18(9):1532-34.

26. Shpynov S, Fournier PE, Rudakov N, Raoult D. "Candidatus rickettsia tarasevichiae" in Ixodes persulcatus ticks collected in Russia. Ann N Y Acad Sci. 2003:990:162-72

27. Katargina O, Geller J, Ivanova A, Varv K, Tefanova V, Vene S, et al. Detection and identification of Rickettsia species in Ixodes tick populations from Estonia. Ticks Tick Borne Dis. 2015;6(6):689-94. 
28. Hiraoka H, Shimada Y, Sakata Y, Watanabe M, Itamoto K, Okuda M, et al. Detection of rickettsial DNA in ixodid ticks recovered from dogs and cats in Japan. J Vet Med Sci. 2005;67(12):1217-22.

29. Cheng WY, Zhao GH, Jia YQ, Bian QQ, Du SZ, Fang YQ, et al.

Characterization of Haemaphysalis flava (Acari: Ixodidae) from Qingling subspecies of giant panda (Ailuropoda melanoleuca qinlingensis) in Qinling Mountains (Central China) by morphology and molecular markers. PLoS One. 2013;8(7):e69793.

30. Jado I, Escudero R, Gil H, Jimenez-Alonso Ml, Sousa R, Garcia-Perez AL, et al. Molecular method for identification of Rickettsia species in clinical and environmental samples. J Clin Microbiol. 2006:44(12):4572-76.

31. Regnery RL, Spruill CL, Plikaytis BD. Genotypic identification of rickettsiae and estimation of intraspecies sequence divergence for portions of two rickettsial genes. J Bacteriol. 1991;173(5):1576-89.

32. Liu GP, Ren QM, He SX, Wang F, Yang J. Distribution and medical importance of ticks in three provinces of northeast China. Chin J Hyg Insect \& Equip. 2008;14(1):39-42 (in Chinese).

33. Moyer MW. Tick trouble. Nature. 2015;524(7566):406-08.

34. Sun Y, Jiang HR, Cao WC, Fu WM, Ju WD, Wang X. Prevalence of Candidatus Rickettsia tarasevichiae-like bacteria in ixodid ticks at 13 Sites on the Chinese-Russian border. J Med Entomol. 2014;51(6):1304-07.

35. Mediannikov OY, Sidelnikov Y, Ivanov L, Mokretsova E, Fournier PE, Tarasevich I, et al. Acute tick-borne rickettsiosis caused by Rickettsia heilongjiangensis in Russian Far East. Emerg Infect Dis. 2004;10(5):810-17.

36. Speck S, Derschum H, Damdindorj T, Dashdavaa O, Jiang J, Kaysser P, et al. Rickettsia raoultii, the predominant Rickettsia found in Mongolian Dermacentor nuttalli. Ticks Tick Borne Dis. 2012;3(4):227-31.

37. Socolovschi C, Mediannikov O, Raoult D, Parola P. The relationship between spotted fever group Rickettsiae and ixodid ticks. Vet Res. 2009;40(2):34.

38. Matsumoto K, Parola P, Rolain JM, Jeffery K, Raoult D. Detection of "Rickettsia sp. strain Uilenbergi" and "Rickettsia sp. strain Davousti" in Amblyomma tholloni ticks from elephants in Africa. BMC Microbiol. 2007;7:74.

39. Palomar AM, Portillo A, Crespo A, Santibanez S, Mazuelas D, Oteo JA Prevalence of 'Candidatus Rickettsia vini' in Ixodes arboricola ticks in the North of Spain, 2011-2013. Parasit Vectors. 2015;8:110.

40. Tamura K, Stecher G, Peterson D, Filipski A, Kumar S. MEGA6: molecular evolutionary genetics analysis version 6.0. Mol Biol Evol. 2013;30(12):2725-29.

\section{Submit your next manuscript to BioMed Central and we will help you at every step:}

- We accept pre-submission inquiries

- Our selector tool helps you to find the most relevant journal

- We provide round the clock customer support

- Convenient online submission

- Thorough peer review

- Inclusion in PubMed and all major indexing services

- Maximum visibility for your research

Submit your manuscript at www.biomedcentral.com/submit 